$\begin{array}{ll}\text { Research Square } & \text { Preprints are preliminary reports that have not undergone peer review. } \\ \text { They should not be considered conclusive, used to inform clinical practice, } \\ \text { or referenced by the media as validated information. }\end{array}$

\title{
Association Between Personal Values in Adolescence and Subjective Well- Being and Subjective Health Status in Adulthood: A Cross-Sectional Study with Retrospective Recall
}

Mako lida

The University of Tokyo

Kazuhiro Watanabe

The University of Tokyo

Naonori Yasuma

The University of Tokyo

Daisuke Nishi

The University of Tokyo

Norito Kawakami ( $\nabla$ nkawakami@m.u-tokyo.ac.jp )

The University of Tokyo https://orcid.org/0000-0003-1080-2720

Research article

Keywords: health, well-being, value of life, adolescent, youth

Posted Date: April 24th, 2020

DOl: https://doi.org/10.21203/rs.3.rs-22887/v1

License: (c) (1) This work is licensed under a Creative Commons Attribution 4.0 International License. Read Full License 


\section{Abstract}

Backgrounds: Subjective well-being and subjective health status are significant indicators of healthy lives, and might be influenced by personal values shaped in adolescence. However, there are no studies that have examined the association between personal values in adolescence and subjective well-being in adulthood. The purpose of this study was to investigate this association in a large community adult sample in Japan.

Methods: This was a cross-sectional study with retrospective recall, using data from a Japanese study on stratification, health, income, and neighborhood (JSHINE) survey. We used data for demographic variables and outcome variables (i.e., meaning in life, life satisfaction, and subjective health status) in a Wave 1 survey, and data regarding personal values (i.e., value priorities based on Schwartz's theory of basic values and commitment to values) at the age of 15 in a Wave 3 survey. Multiple linear regression analysis was conducted to investigate the association between personal values at the age of 15 and meaning in life, life satisfaction, and subjective health status in adulthood.

Results: A total of 2,413 adults from the J-SHINE sample were included in the analysis. The adolescent values of "having influence on society," "actively challenging," "having and keeping a belief," "exploring what you were interested in," "graduating from a famous school," and commitment to values were positively and significantly associated, while "being evaluated by others" in adolescence was negatively associated with meaning in life in adulthood. At the same time, commitment to values in adolescence was positively and significantly associated with life satisfaction in adulthood. With subjective health status in adulthood, the adolescent value of "graduating from a famous school" had a positive and significant correlation, while "maintain a stable life" had a negative and significant association.

Conclusions: Personal values related to openness to change and self-enhancement, and commitment to values in adolescence might be associated with better subjective well-being and subjective health status in adulthood. The findings could be useful for programs that invest in adolescence, which can bring many benefits to adulthood.

\section{Background}

Ensuring healthy lives and promoting well-being for all at all ages has been one of the most crucial world goals aimed at sustainable societies (1). Subjective well-being, which is defined as a person's cognitive and affective evaluations of their life as a whole (2) has gained increased researchers' interest in recent years. Subjective well-being includes broad aspects such as life satisfaction (evaluative well-being), positive emotions (hedonic well-being), and meaning in life (eudemonic well-being). Subjective well-being has correlations with significant outcomes, such as a lower risk of chronic physical illness and mortality (35). Meaning in life is an eudemonic aspect of subjective well-being. Having a high level of meaning in life has been associated with low depression and anxiety (6), and a high level in the development of a coherent sense of one's identity $(7,8)$. In comparison, life satisfaction, which refers to a cognitive judgment about a person's own life, is defined as evaluative or hedonic aspects of subjective well-being (9). Higher life satisfaction was reported to be associated with lower mortality $(10,11)$ and lower levels of sleep complaints $(12)$.

Health is one of the dimensions of well-being. A subjective evaluation of one's health, i.e., subjective health status, is also a good indicator of morbidity and mortality. For example, a meta-analysis reported that persons with "poor" self-rated health had a two times higher mortality risk than persons with "excellent" self-rated health (13). Also, subjective health status appears to modify associations between functional impairment and morbidity (14, 15). It is also known that subjective health status is a strong determinant of subjective well-being (16).

Recently, some researchers have argued that there is an association between personal values and subjective well-being. Personal values have been defined as broad and desirable goals, varying in importance and guiding principles in people's lives $(17,18)$. Personal values refer to an individual's way of facing the world, which both consciously and unconsciously drives their long-term actions throughout their lives (19). Schwartz, one of the leading researchers of personal values, proposed that the content and structure of personal values consists of four general objectives and ten motivational types of goals: selftranscendence (universalism and benevolence), conservation (conformity, tradition, and security), openness to change (self-direction, stimulation, and hedonism), and self-enhancement (hedonism, achievement, and power) $(20,21)$. Previous studies have investigated the associations between personal values and subjective well-being based on Schwarz's theory. For example, Sagiv and Schwartz (17) found that achievement, stimulation, and self-direction values were positively associated, while tradition, conformity, and security values were negatively associated with subjective well-being among Israeli and German university students and adults. Bobowik et al. (22) found that stimulation, self-direction, universalism, and benevolence were correlated positively, while tradition, conformity, security, and power correlated negatively with subjective well-being among European adults. Joshanloo and Ghaedi (23) found that achievement and self-direction were positively associated, while tradition and universalism were negatively associated with subjective well-being among Iranian university students. These previous studies were based on self-determination theory, which argued that intrinsically motivating values provide the fulfillment of psychological needs and thus promote subjective well-being $(17,22-24)$. Therefore, personal values related to self-transcendence, openness to change, and achievement tend to be positively associated, while conservation and power tend to be negatively associated with subjective well-being. Another approach for personal values research is measuring the extent that people are committed to specific values (25). This includes not only what goals people pursue, but also why people pursue them, which may then contribute to subjective well-being (26). A previous study found that commitment to values was also associated with subjective well-being $(17,27)$.

However, no studies have examined how personal values in adolescence are related to subjective well-being in adulthood. All previous studies investigated these associations at a given time point (e.g., only in adolescence $(28)$ or in adulthood $(17,22,23)$ ). During adolescence, an individual acquires the physical, emotional, and social resources that are the foundation for later life (29). Thus, subjective well-being in adulthood might be influenced by personal values shaped in adolescence. Therefore, it is essential to investigate the long-term associations between personal values in adolescence and subjective well-being in adulthood. This study could be useful for programs that invest in adolescence, which can bring many benefits to adult life. 
The purpose of this study is to investigate the association between personal values in adolescence and subjective well-being and subjective health status in adulthood in a large community adult sample in Japan. We hypothesized that personal values in adolescence related to self-transcendence, openness to change, and achievement, and how people commit themselves to values in adolescence would be positively associated with subjective well-being and subjective health status in adulthood.

\section{Methods \\ Study Design and Setting}

This was a cross-sectional study with retrospective recall using data from a Japanese study on stratification, health, income, and neighborhood (J-SHINE) survey (30). The J-SHINE survey is a prospective cohort study aimed at clarifying the complex associations between social factors and various health policy evaluations. The J-SHINE survey randomly sampled adult community residents from a registry in each of four municipalities (two in Tokyo and two in neighboring prefectures). The Wave 1 survey was from July 2010 to February 2011, the Wave 2 survey from August 2011 to December 2011 , and the Wave 3 survey in 2017. We used data regarding demographic variables and outcome variables (i.e., meaning in life, life satisfaction, and subjective health status) in the Wave 1 survey and data of personal values at the age of 15 in the Wave 3 survey. The study protocol and informed consent procedure were approved by the ethics committee of the Graduate School of Medicine of The University of Tokyo [No.630-7,3361].

\section{Participants}

Study participants were adult community residents recruited in the J-SHINE survey. Eligibility criteria of the study were adult community inhabitants aged 20 to 50 years old who were selected from the registry in four municipalities (two in the Tokyo metropolitan area and two in neighboring prefectures). Systematic sampling was conducted for each unit. Except for age, there were no inclusion and exclusion criteria. Trained surveyors visited the home of the inhabitants after sending an invitation letter. If they agreed to participate in the study, the participants were asked to provide informed consent and answered the selfreport questionnaire by using a computer-aided personal instrument (CAPI). For those who were unfamiliar with computer use, a personal interview with the CAPI was provided.

\section{Measurements}

All variables in this study (personal values at the age of 15 , meaning in life, life satisfaction, subjective health status, and covariates) were measured by selfreport questionnaires.

Personal values at the age of 15 were measured by two components: value priorities and degree of commitment to the values. For measurement of the value priorities, we used a list of 11 values $(31,32)$, which were developed based on the 57-item Protrait Values Questionnaire (PVQ-57) (33): not bothering others, being evaluated by others, having and keeping a belief, economically succeeding, improving society, exploring what you were interested in, having influence on society, actively challenging, cherishing familiar people, graduating from a famous school, and maintain a stable life. Respondents were asked to recall their value priorities at the age of 15 ("When you were 15-16 years old, how important did you think the following values were in your life?) and rate for each on a seven-point Likert scale ( $1=$ Not at all, 7 = Very important). Commitment to the values was measured by the Personal Values Questionnaire $\otimes(P V Q-\bigotimes)$ (34). The

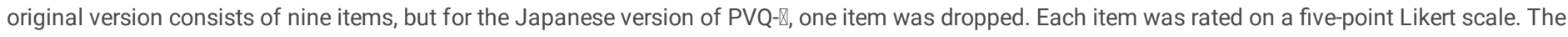

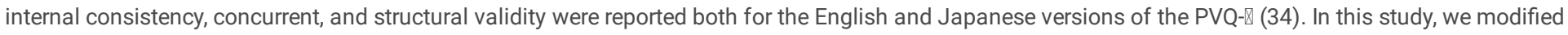
the PVQ- $囚$ questions to the past tense and asked participants to rate their commitment to a value that was most important for them at the age of 15 . Internal consistency and factor-based and construct validity were already found to be acceptable (Watanabe et al., under review). The total score was calculated, and higher ratings indicate more commitment to the important values.

Meaning in life was measured by the Meaning in Life Questionnaire (MLQ) (6). The MLQ consists of two five-item subscales; presence of meaning in life and search for meaning in life. All items were rated on a seven-point Likert scale ranging from 1 (Strongly disagree) to 7 (Strongly agree). We calculated the total score of each subscale and used this for analyses. Higher scores indicate a higher meaning in life. The original English scale was translated into Japanese and preliminarily tested, and it proved to have an acceptable level of internal consistency reliability and content validity (6).

Life satisfaction was also measured by one item: "How satisfied are you with your current life in general?" The item was rated on a five-point Likert scale ( 1 = Satisfied, 5 = Dissatisfied). This question was ab item from the national survey of Social Stratification and Social mobility (SSM) (35). The score of life satisfaction was reverse coded, with a higher score meaning a more satisfying life.

Subjective health status was measured by one item, "How is your current health condition?" The item was developed in a national survey, the Comprehensive Survey of Living Conditions. This survey was conducted to investigate basic matters such as health, medical care, welfare, pension, income, etc., by the Household Statistics Office, the Ministry of Health, Labour and Welfare, Japan (Ministry of Health, Labour and Welfare online (36). The item was rated on a five-point Likert scale ( 1 = Good, 5 = Not good). The score for subjective health status was reverse coded, with a higher score meaning a better health condition.

As the covariates, demographic variables, and one's circumstances at the age of 15 were measured. The demographic variables included gender (male [reference], female), age, educational status (junior high school [reference], senior high school, professional school, university), marital status (not married [reference], married), work status (not working [reference], working, absence), household income (Japanese yen) (< 3 million [reference], $3 \sim 5$ million, $5 \sim 7.5$ 
million, > 7.5 million, not known). One's circumstances at the age of 15 consisted of one item, rated on a 5-point Likert scale ranging from 1 (very poor) to 5 (very rich).

\section{Statistical analysis}

Participants who completed all the variables used in the study were included in the analyses. First, descriptive statistics among the completers were calculated. For the main analysis, multiple linear regression analysis was done to investigate the association between personal values at the age of 15 and meaning in life, life satisfaction, and subjective health status. The analysis estimated both crude associations and adjusted associations for the covariates. For the categorical covariates (gender, educational status, marital status, work status, and household income), dummy variables were created and entered into the models. Statistical analysis was done with SPSS (IBM SPSS Statistics for Windows, version 22.0 Armonk, NY, USA).

\section{Results}

Figure 1 shows a participant flowchart. Of the 13,920 people in the initially selected sample, a total of 4,385 respondents participated in the Wave 1 survey (response: $31.3 \%$ ), and a total of 2,961 respondents participated in the Wave 2 survey (response rate: $67.8 \%$ ). A total of 2,787 respondents (63.6\%) responded to the Wave 3 survey. After excluding participants with missing questionnaires, we included data from 2,413 respondents in the analyses.

Table 1 shows the descriptive statistics of the participants. The ratio of males and females was approximately equal. In the whole sample, most were middleaged, married, and working; more than half had gone to high school or had some college education and a salary of 5 million yen or more. About $60 \%$ of respondents answered that their circumstances at 15 years old were ordinary. Table 1 also shows the means and standard deviations of the outcome variables. The means and standard deviations for meaning in life, life satisfaction, and subjective health status were $43.5 \pm 10.3,3.7 \pm 1.0$, and $3.9 \pm 1.0$, respectively. 
Table 1

Participant demographics $(\mathrm{N}=2,413)$

\begin{tabular}{|c|c|c|c|c|}
\hline & $\mathrm{N}(\%)$ & Range & Mean (SD) & Missing (\%) \\
\hline Gender & & & & $0(0.0)$ \\
\hline Male & $1,081(44.8)$ & & & \\
\hline Female & $1,332(55.2)$ & & & \\
\hline Age & & & $38.0(7.0)$ & $0(0.0)$ \\
\hline Educational status & & & & $0(0.0)$ \\
\hline Junior high school & $69(2.9)$ & & & \\
\hline Senior high school & $550(22.8)$ & & & \\
\hline Professional school & $747(31.0)$ & & & \\
\hline University & $1,047(43.4)$ & & & \\
\hline Marital status & & & & $0(0.0)$ \\
\hline Not married & $607(25.2)$ & & & \\
\hline Married & $1,806(74.8)$ & & & \\
\hline Work status & & & & $0(0.0)$ \\
\hline Not working & $480(19.9)$ & & & \\
\hline Working & $1,878(77.8)$ & & & \\
\hline Absence & $55(2.3)$ & & & \\
\hline Income (Japanese Yen) & $251(79.2)$ & & & \\
\hline$<3$ million & $172(7.1)$ & & & \\
\hline $3 \sim 5$ million & 407 (16.9) & & & \\
\hline $5 \sim 7.5$ million & $609(25.2)$ & & & \\
\hline$>7.5$ million & $823(34.1)$ & & & \\
\hline Unknown & $402(16.7)$ & & & \\
\hline SES at 15 years old & & $1-5$ & $3.0(0.8)$ & $0(0.0)$ \\
\hline Meaning in life & & $10-70$ & $43.5(10.3)$ & $0(0.0)$ \\
\hline Presence of meaning & & & $20.8(6.1)$ & $0(0.0)$ \\
\hline Search for meaning & & & $22.7(6.2)$ & $0(0.0)$ \\
\hline Life satisfaction & & $1-5$ & $3.7(1.0)$ & $0(0.0)$ \\
\hline Subjective health status & & $1-5$ & $3.9(1.0)$ & $0(0.0)$ \\
\hline
\end{tabular}

Table 2 shows the association of personal values at the age of 15 and commitment to the values with subjective well-being and subjective health status. With the two factors of meaning in life (presence of meaning in life and search for meaning in life), "having influence on society" ( $\beta=0.105$ for presence of meaning in life, $\beta=0.064$ for search for meaning in life) and "actively challenging" ( $\beta=0.137$ for presence of meaning in life, $\beta=0.117$ for search for meaning in life) were positively associated and remained significant after the adjustment. "Having and keeping a belief" $(\beta=0.105, p<0.001)$ and commitment to the values $(\beta=0.166, p<0.001)$ were positively and significantly associated with the presence of meaning in life. On the other hand, "being evaluated by others" was significantly and negatively associated $(\beta=-0.064, p=0.004)$. These associations were still significant after the adjustment. With the search for meaning in life, "exploring what you were interested in" $(\beta=0.066, p=0.007)$ and "graduating from a famous school" $(\beta=0.071, p=0.003)$ were positively and significantly associated. These associations were still significant after the adjustment. With life satisfaction, "cherishing familiar people" ( $\beta=0.058, p=$ $0.015)$ and "graduating from a famous school" $(\beta=0.100, p<0.001)$ were positively and significantly associated in the crude model. Commitment to the values was also positively and significantly associated $(\beta=0.105, p<0.001)$. However, after the adjustment, only commitment to the values remained significant $(\beta=0.070, p=0.001)$. With subjective health status, "graduating from a famous school" was positively and significantly associated both in the crude $(\beta=0.094, p<0.001)$ and adjusted model $(\beta=0.063, p=0.016)$. In the adjusted model, "maintain a stable life" also had a significant and negative association $(\beta=-0.053, p=0.046)$. 
Table 2

Associations between personal values in adolescence and health and well-being in adulthood $(\mathrm{N}=2,413)$

\begin{tabular}{|c|c|c|c|c|c|c|c|c|c|c|c|c|c|c|c|}
\hline & \multicolumn{8}{|c|}{ Meaning in life } & \multirow{2}{*}{\multicolumn{2}{|c|}{ Life satisfaction }} & & & \multicolumn{3}{|c|}{ Subjective health stat } \\
\hline & \multicolumn{4}{|c|}{ Presence of meaning in life } & \multicolumn{4}{|c|}{ Search for meaning in life } & & & & & & & \\
\hline & \multicolumn{2}{|l|}{ Crude } & \multicolumn{2}{|c|}{ Adjusted§ } & \multicolumn{2}{|l|}{ Crude } & \multicolumn{2}{|c|}{ Adjusted§ } & \multicolumn{2}{|l|}{ Crude } & \multicolumn{2}{|c|}{ Adjusted§ } & \multicolumn{2}{|l|}{ Crude } & \multirow{2}{*}{$\frac{A}{\beta}$} \\
\hline & $\beta$ & $p$ & $\beta$ & $p$ & $\beta$ & $p$ & $\beta$ & $p$ & $\beta$ & $p$ & $\beta$ & $p$ & $\beta$ & $p$ & \\
\hline \multicolumn{16}{|l|}{$\begin{array}{l}\text { Personal } \\
\text { values at age } \\
15\end{array}$} \\
\hline $\begin{array}{l}\text { Not } \\
\text { bothering } \\
\text { others }\end{array}$ & 0.007 & 0.748 & 0.002 & 0.934 & 0.004 & 0.865 & 0.003 & 0.886 & 0.029 & 0.231 & 0.024 & 0.285 & -0.025 & 0.305 & $-c$ \\
\hline $\begin{array}{l}\text { Being } \\
\text { evaluated by } \\
\text { others }\end{array}$ & -0.064 & 0.004 & -0.055 & 0.013 & 0.042 & 0.067 & 0.043 & 0.063 & -0.041 & 0.082 & -0.041 & 0.062 & -0.003 & 0.894 & $-c$ \\
\hline $\begin{array}{l}\text { Having and } \\
\text { keeping a } \\
\text { belief }\end{array}$ & 0.105 & $<0.001$ & 0.109 & $<0.001$ & 0.038 & 0.138 & 0.038 & 0.139 & -0.007 & 0.803 & 0.010 & 0.692 & 0.029 & 0.269 & 0 \\
\hline $\begin{array}{l}\text { Economically } \\
\text { succeeding }\end{array}$ & -0.031 & 0.216 & -0.032 & 0.205 & -0.033 & 0.189 & -0.036 & 0.162 & -0.049 & 0.061 & -0.041 & 0.098 & 0.004 & 0.886 & 0 \\
\hline $\begin{array}{l}\text { Improving } \\
\text { society }\end{array}$ & 0.029 & 0.270 & 0.025 & 0.345 & -0.004 & 0.880 & -0.005 & 0.868 & -0.009 & 0.743 & -0.011 & 0.673 & -0.016 & 0.559 & $-c$ \\
\hline $\begin{array}{l}\text { Exploring } \\
\text { what you } \\
\text { were } \\
\text { interested in }\end{array}$ & -0.032 & 0.175 & -0.020 & 0.414 & 0.066 & 0.007 & 0.057 & 0.021 & -0.040 & 0.112 & 0.002 & 0.936 & -0.026 & 0.296 & $-c$ \\
\hline $\begin{array}{l}\text { Having } \\
\text { influence on } \\
\text { society }\end{array}$ & 0.105 & $<0.001$ & 0.103 & $<0.001$ & 0.064 & 0.015 & 0.064 & 0.016 & -0.011 & 0.672 & 0.012 & 0.640 & -0.050 & 0.066 & $-c$ \\
\hline $\begin{array}{l}\text { Actively } \\
\text { challenging }\end{array}$ & 0.137 & $<0.001$ & 0.130 & $<0.001$ & 0.117 & $<0.001$ & 0.119 & $<0.001$ & 0.037 & 0.169 & 0.018 & 0.470 & 0.045 & 0.094 & 0 \\
\hline $\begin{array}{l}\text { Cherishing } \\
\text { familiar } \\
\text { people }\end{array}$ & 0.011 & 0.621 & 0.010 & 0.672 & 0.016 & 0.482 & 0.026 & 0.273 & 0.058 & 0.015 & 0.039 & 0.082 & 0.042 & 0.082 & 0 \\
\hline $\begin{array}{l}\text { Graduating } \\
\text { from a } \\
\text { famous } \\
\text { school }\end{array}$ & 0.012 & 0.603 & -0.012 & 0.631 & 0.071 & 0.003 & 0.058 & 0.024 & 0.100 & $<0.001$ & 0.032 & 0.198 & 0.094 & $<0.001$ & 0 \\
\hline $\begin{array}{l}\text { Maintain a } \\
\text { stable life }\end{array}$ & 0.012 & 0.622 & 0.011 & 0.658 & -0.039 & 0.134 & -0.039 & 0.136 & 0.047 & 0.078 & 0.030 & 0.221 & -0.049 & 0.064 & $-c$ \\
\hline PVQQ & 0.166 & $<0.001$ & 0.156 & $<0.001$ & 0.033 & 0.138 & 0.031 & 0.177 & 0.105 & $<0.001$ & 0.070 & 0.001 & 0.040 & 0.085 & 0 \\
\hline
\end{tabular}

Age, sex, educational status, marital status, working status, household income, SES at 15 years old were adjusted.

tA higher score indicates a better health condition.

\section{Discussion}

The results indicated that some personal values in adolescence were significantly associated with meaning in life, life satisfaction, and subjective health status in adulthood. To our knowledge, this was the first study to investigate the association between adolescent personal values and subjective well-being and subjective health status in adulthood in a cross-sectional study with a retrospective recall in a large community adult sample in Japan. Adolescent personal values related to openness to change and self-enhancement, as well as based on intrinsic motivation, were positively related to subjective well-being in adulthood. Additionally, commitment to values in adolescence might also be important for better subjective well-being in adulthood. On the other hand, personal values related to conservation or extrinsic motivation in adolescence might be adverse to subjective well-being and subjective health status in adulthood. The findings from this study suggest the necessity of educational investments that promote the independence of beliefs, readiness for change, the pursuit of one's interests, and the aim for relative success in adolescents for better subjective well-being in adulthood.

Personal values related to openness to change and self-enhancement in adolescence might be valuable for better subjective well-being in adulthood. Adolescent personal values such as "having and keeping a belief," "exploring what you were interested in," and "actively challenging," which are considered as values related to openness to change, and "having influence on society," which is considered as values related to self-enhancement, were positively associated with meaning in life in adulthood. An underlying mechanism for the associations could be explained by intrinsic motivation. The values related to openness to change and self-enhancement might satisfy basic psychological needs, such as autonomy, relatedness, and competence, and be directed toward intrinsic 
goals $(24,37)$. Such intrinsic motivation might be important for better subjective well-being. Previous studies indicated that personal values directed toward intrinsic goals such as self-transcendence, openness to change, and achievement should have positive and cross-sectional relationships with subjective wellbeing in adulthood $(18,22,23,27)$. The interesting findings were that personal values directed toward the intrinsic goal in adolescence might also be important for better subjective well-being in adulthood. Adolescents who make efforts toward self-actualization based on intrinsic motivation would realize their goal and experience significant meaning in life when they grew up. Additionally, the result of commitment to values was associated with an improved presence of meaning in life, life satisfaction, and subjective health status, which was consistent with a previous study (27). Being committed deeply to their values in adolescence might empower a person to develop goals congruent with such values (27) and perceive high subjective well-being in adulthood, whether or not the value was based on openness to change and self-enhancement, and intrinsic motivation.

Most of the significant associations observed in the study were those with meaning in life, which is the eudemonic aspect of subjective well-being. Therefore, eudemonic well-being in adulthood might be sensitively associated with personal values in adolescence. Eudemonia has been said to have occurred when people's life activities were most congruent and were holistically engaged (37). Thus, eudemonic well-being might have increased as a result of taking actions based on personal values directed toward intrinsic goals during adolescence. Eudemonic well-being seems to be more valuable than hedonic well-being when considering long-term wellness and positive psychological functioning $(38,39)$. Eudemonic theories insist that even though people feel hedonic pleasure, not all desires that a person might value promote wellness. Meanwhile, eudemonic living could improve specific physiological systems relating to immunological functioning and health promotion (37). Indeed, previous studies indicated that high eudemonic well-being reduced the incidence of coronary heart disease (40), stroke (41), and depression (42). Therefore, this study suggested an interesting possibility that personal values in adolescence could determine such important outcomes in adults.

On the contrary, adolescent personal values related to conservation or extrinsic motivation might be adverse to subjective well-being and subjective health status in adulthood. "Being evaluated by others," which is considered as a value related to self-enhancement, but directed toward extrinsic goals in adolescence, was negatively associated with the presence of meaning in life in adulthood. "Maintain a stable life", which is considered as a value related to conservation in adolescence, was also negatively associated with subjective health status in adulthood. These findings were consistent with previous crosssectional studies that investigated the relationship in adulthood $(17,22)$. According to self-determination theory, extrinsic motivation refers to the performance of an activity to attain some separable outcomes or goals rather than for their inherent enjoyment (24). Adolescents who prioritize the values of "being evaluated by others" or "maintain a stable life" might pursue extrinsic goals, such as money, fame, public image, and control over others. Such extrinsic motivation could not satisfy their psychological needs (17), and they were likely to acquire worse subjective well-being and subjective health status in the future.

Contrary to the hypotheses, "graduating from a famous school" was significantly and positively associated with subjective well-being and subjective health status, even though this value pertained to extrinsic motivation such as fame or public image. One possibility is the mediative effect of socioeconomic status. A previous study argued that socioeconomic status in adulthood might mediate the association between graduating from school in adolescence and subjective well-being in adulthood (32). This consideration could also adapt to the positive association between a prioritized value of graduating from a famous school in adolescence and subjective well-being and subjective health status in adulthood.

This study has several limitations. First, due to the low response rate at the baseline, selection bias might be induced if people that did not participate in the survey had worse subjective well-being and subjective health status and low personal values. Second, recall bias might have occurred because of the study design that asked the participants to remember personal values at the age of 15 . The bias could result in the overestimation of the association because participants who had higher levels of subjective well-being and subjective health status were more likely to recall better personal values. Third, some significant covariates were not measured in this study, such as medical history, which may confound the association. Such covariates might cause confounding bias for the associations. Fourth, the validity and reliability of the measurement of personal values in adolescence used in this study have not been completely evaluated, thus information bias and high random errors might have occurred.

\section{Conclusions}

This study indicated that personal values related to openness to change and self-enhancement, as well as intrinsic motivation, were associated with better subjective well-being in adulthood. Additionally, commitment to values in adolescence was associated with better subjective well-being in adulthood. This study also showed that values related to conservation or extrinsic motivation in adolescence were associated with adverse subjective well-being and subjective health status in adulthood.

\section{List Of Abbreviations}

J-SHINE: Japanese study on stratification, health, income, and neighborhood; CAPI: computer-aided personal instrument; PVQ-57: 57-item Portrait Values Questionnaire; PVQ-邓: Personal Values Questionnaire $\Downarrow ;$ MLQ: Meaning in Life Questionnaire; SSM: Social Stratification and Social mobility

\section{Declarations}

\section{Ethics approval and consent to participate}

The study protocol and informed consent procedure were approved by the ethics committees of the Graduate School of Medicine of The University of Tokyo [No.630-7,3361].

\section{Consent for publication}


Not applicable.

\section{Availability of data and materials}

The data of this study are available from the corresponding author on request.

\section{Competing interests}

The authors declare that they have no competing interests.

\section{Funding}

This study was partly supported by MEXT KAKENHI Grant Number JP21119003, JSPS KAKENHI Grant Number JP16H06395, 16H06398, and 16K21720. The Japanese Study on Stratification, Health, Income,and Neighborhood (J-SHINE) was supported by a Grant-in-Aid for Scientific Research on Innovative Areas (No. 1119002) from the Ministry of Education, Culture, Sports, Science and Technology, Japan. The funders had no role in the study design, data collection, and analysis, the writing of the report, or the decision to submit the paper for publication.

\section{Authors' contributions}

$\mathrm{MI}$ analyzed and interpreted the results and wrote the manuscript. KW, NY, DN, and NK made substantial contributions to the conception and design of the study, interpretation of the results, a critical revision of the article for important intellectual content. All authors read and approved the final version of the manuscript.

\section{Acknowledgments}

The authors would like to thank the data control committee of the Japanese study on stratification, health, income, and neighborhood (J-SHINE) research group for providing us the data. We also extend our sincere appreciation to Professor Hideki Hashimoto and Lecturer Daisuke Takagi for their help in data handling.

\section{References}

1. United Nations. Sustainable Development Goals 3: Good health and well-being. https://sustainabledevelopment/health/. Accessed 23 May 2020.

2. Lucas RE, Oishi S, Diener E. Subjective Well-Being: The Science of Happiness and Life Satisfaction. 2nd ed: Oxford University Press; 2009.

3. Steptoe AP, Deaton AP, Stone AAP. Subjective wellbeing, health, and ageing. Lancet, The. 2015;385(9968):640-8.

4. Diener E, Chan MY. Happy People Live Longer: Subjective Well-Being Contributes to Health and Longevity. Applied Psychology: Health and Well-Being. 2011;3(1):1-43.

5. Martin-Maria N, Miret M, Caballero FF, Rico-Uribe LA, Steptoe A, Chatterji S, et al. The Impact of Subjective Well-being on Mortality: A Meta-Analysis of Longitudinal Studies in the General Population. Psychosomatic Medicine. 2017;79(5):565-75.

6. Steger MF, Frazier P, Oishi S, Kaler M. The meaning in life questionnaire: Assessing the presence of and search for meaning in life. Journal of Counseling Psychology. 2006;53(1):80-93.

7. Heine SJ, Proulx T, Vohs KD. The meaning maintenance model: On the coherence of social motivations. Personality and social psychology review. 2006;10(2):88-110.

8. Steger MF, Oishi S, Kashdan TB. Meaning in life across the life span: Levels and correlates of meaning in life from emerging adulthood to older adulthood. The Journal of Positive Psychology. 2009;4(1):43-52.

9. Diener E, Suh EM, Lucas RE, Smith HL. Subjective Well-Being: Three Decades of Progress. Psychological Bulletin. 1999;125(2):276-302.

10. Chida Y, Steptoe A. Positive psychological well-being and mortality: a quantitative review of prospective observational studies. Psychosomatic medicine. 2008;70(7):741-56.

11. Lacruz ME, Emeny RT, Baumert J, Ladwig KH. Prospective association between self-reported life satisfaction and mortality: Results from the MONICA/KORA Augsburg S3 survey cohort study. BMC Public Health. 2011;11(1):579-.

12. Brand S, Beck J, Hatzinger M, Harbaugh A, Ruch W, Holsboer-Trachsler E. Associations between satisfaction with life, burnout-related emotional and physical exhaustion, and sleep complaints. World Journal of Biological Psychiatry. 2010;11(5):744-54.

13. DeSalvo KB, Bloser N, Reynolds K, He J, Muntner P. Mortality prediction with a single general self-rated health question. A meta-analysis. J Gen Intern Med. 2006;21(3):267-75.

14. Emmelin M, Weinehall L, Stegmayr B, Dahlgren L, Stenlund H, Wall S. Self-rated ill-health strengthens the effect of biomedical risk factors in predicting stroke, especially for men - an incident case referent study. Journal of Hypertension. 2003;21(5):887-96.

15. May M, Lawlor DA, Brindle P, Patel R, Ebrahim S. Cardiovascular disease risk assessment in older women: can we improve on Framingham? British Women's Heart and Health prospective cohort study. HEART. 2006;92(10):1396-401.

16. Sun S, Chen J, Johannesson M, Kind P, Burström K. Subjective Well-Being and Its Association with Subjective Health Status, Age, Sex, Region, and Socioeconomic Characteristics in a Chinese Population Study. Journal of Happiness Studies. 2016;17(2):833-73.

17. Sagiv L, Schwartz SH. Value priorities and subjective well-being: direct relations and congruity effects. European Journal of Social Psychology. 2000;30(2):177-98. 
18. Sortheix FM, Schwartz SH. Values that Underlie and Undermine Well-Being: Variability Across Countries. European Journal of Personality. 2017;31(2):187201.

19. Kasai K, Fukuda M. Science of recovery in schizophrenia research: brain and psychological substrates of personalized value. NPJ schizophrenia. 2017;3(1):14-2.

20. Schwartz SH. Universals in the content and structure of values: Theoretical advances and empirical tests in 20 countries. Advances in experimental social psychology. 25: Elsevier; 1992. p. 1-65.

21. Schwartz SH. Are there universal aspects in the structure and contents of human-values. Journal of social issues. 1994;50(4):19-45.

22. Bobowik M, Basabe N, Páez D, Jiménez A, Bilbao MÁ. Personal Values and Well-Being among Europeans, Spanish Natives and Immigrants to Spain: Does the Culture Matter? Journal of Happiness Studies. 2011;12(3):401-19.

23. Joshanloo. Value priorities as predictors of hedonic and eudaimonic aspects of well-being. Personality and individual differences. 2009;47(4).

24. Ryan RM, Deci EL. Self-determination theory and the facilitation of intrinsic motivation, social development, and well-being. American psychologist. 2000;55(1):68-78.

25. Sheldon KM, Elliot AJ. Not all Personal Goals are Personal: Comparing Autonomous and Controlled Reasons for Goals as Predictors of Effort and Attainment. Personality and Social Psychology Bulletin. 1998;24(5):546-57.

26. Sheldon KM, Ryan RM, Deci EL, Kasser T. The independent effects of goal contents and motives on well-being: It's both what you pursue and why you pursue it. Personality and social psychology bulletin. 2004;30(4):475-86.

27. Ferssizidis P, Adams LM, Kashdan TB, Plummer C, Mishra A, Ciarrochi J. Motivation for and commitment to social values: The roles of age and gender. Motivation and Emotion. 2010;34(4):354-62.

28. Rask K, Astedt-Kurki P, Laippala P. Adolescent subjective well-being and realized values. J Adv Nurs. 2002;38(3):254-63.

29. Patton GCMD, Sawyer SMMD, Santelli JSMD, Ross DAP, Afifi RP, Allen NBP, et al. Our future: a Lancet commission on adolescent health and wellbeing. Lancet, The. 2016;387(10036):2423-78.

30. Takada M, Kondo N, Hashimoto H. Japanese study on stratification, health, income, and neighborhood: study protocol and profiles of participants. J Epidemiol. 2014;24(4):334-44.

31. Yasuma N, Watanabe K, Matsunaga A, Nishi D, Kawakami N. Personal values in adolescence and suicidality: a cross-sectional study based on a retrospective recall. BMC Psychiatry. 2019;19(1):214-12.

32. Watanabe K, Kawakami N, Nishi D. Association between personal values in adolescence and mental health and well-being in adulthood: a cross-cultural study of working populations in Japan and the United States. Annals of General Psychiatry. 2020;19(1):7.

33. Schwartz SH. An overview of the Schwartz theory of basic values. Online readings in Psychology and Culture. 2012;2(1):11.

34. Doi S, Yokomitsu K, Sakano Y. Personal values questionnaire II: internal consistency and validity. Japanese Journal of Behavior Therapy. 2014;40(1):4555.

35. National Survey of Social Stratification and Social Mobility. http://www.l.u-tokyo.ac.jp/2015SSM-PJ/index.html. Accessed 23 May 2020.

36. Ministry of Health, Labour and Welfare. Comprehensive Survey of Living Conditions. https://www.mhlw.go.jp/toukei/list/20-21tyousa.html\#anchor06. Accessed 23 May 2020.

37. Ryan RM, Deci EL. On happiness and human potentials: a review of research on hedonic and eudaimonic well-being. Annual review of psychology. 2001;52(1):141-66.

38. McMahan EA, Estes D. Hedonic Versus Eudaimonic Conceptions of Well-being: Evidence of Differential Associations With Self-reported Well-being. Social Indicators Research. 2011;103(1):93-108.

39. McMahan EA, Estes D. Measuring Lay Conceptions of Well-Being: The Beliefs About Well-Being Scale. Journal of Happiness Studies. 2011;12(2):267-87.

40. Kim ES, Sun JK, Park N, Kubzansky LD, Peterson C. Purpose in life and reduced risk of myocardial infarction among older U.S. adults with coronary heart disease: a two-year follow-up. Journal of Behavioral Medicine. 2013;36(2):124-33.

41. Kim ES, Sun JK, Park N, Peterson C. Purpose in life and reduced incidence of stroke in older adults: 'The Health and Retirement Study'. Journal of Psychosomatic Research. 2013;74(5):427-32.

42. Wood AM, Joseph S. The absence of positive psychological (eudemonic) well-being as a risk factor for depression: A ten year cohort study. Journal of Affective Disorders. 2009;122(3):213-7.

\section{Figures}




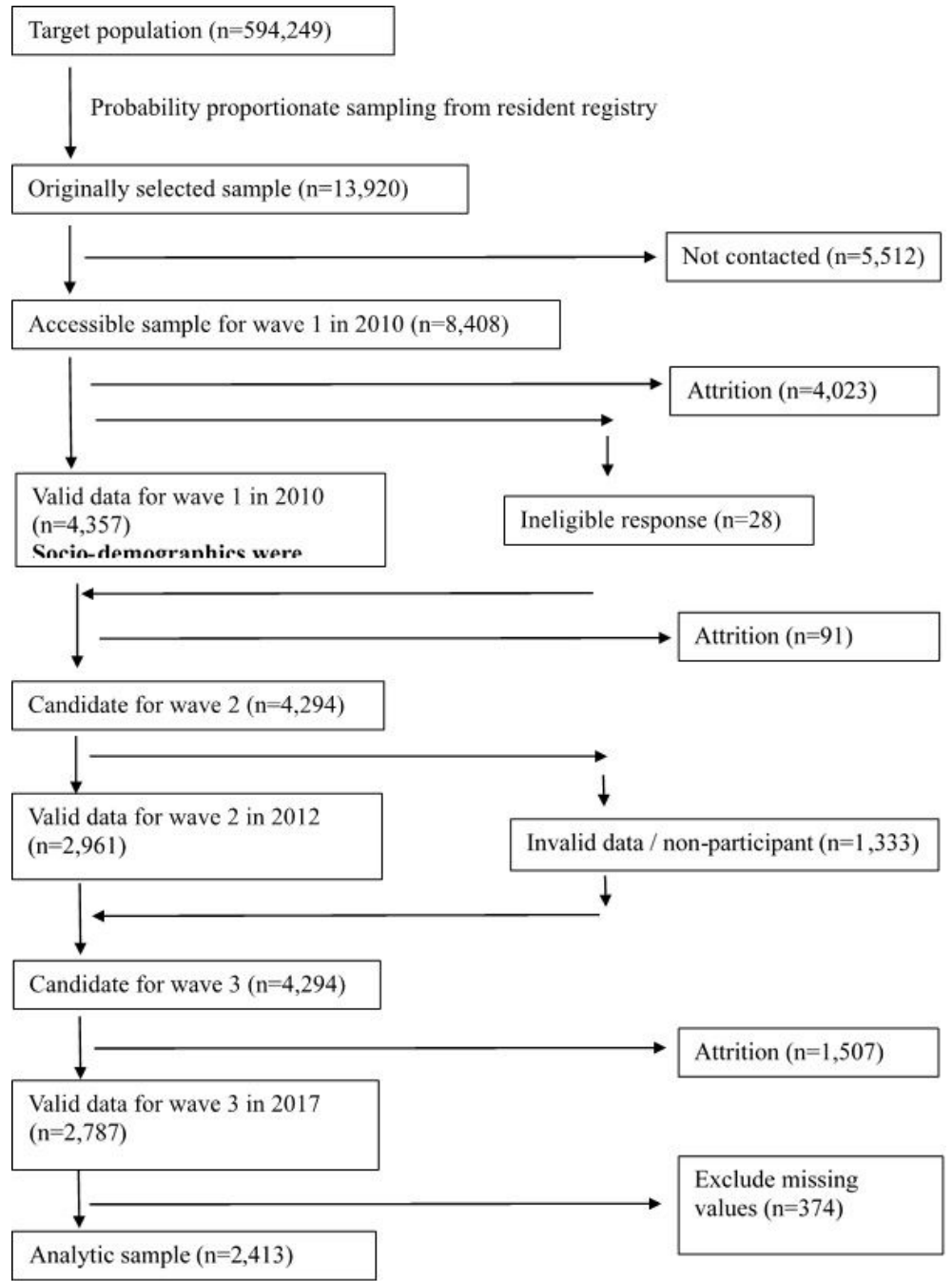

\section{Figure 1}

Flowchart of participant recruitment in J-SHINE. 